Triadic dialogue in oral communication tasks: what are the implications for language learning?

Word count: 7404

\author{
Julie Radford \\ Institute of Education, University of London, Psychology and Human \\ Development, 25 Woburn Square, London WC1H 0AA
}

Judy Ireson

Institute of Education, University of London, Psychology and Human

Development, 25 Woburn Square, London WC1H 0AA

\author{
Merle Mahon \\ University College London, Human Communication Science, Chandler \\ House, 2 Wakefield Street, London WC1N 1PG
}

Language and Education

Accepted April 2005

All correspondence with respect to this article should be addressed to:

Dr Julie Radford, Psychology and Human Development, Institute of Education, 25 Woburn Square, London, WC1H 0AA., UK

Email: j.radford@ioe.ac.uk Tel: 02076126295 
Triadic dialogue in oral communication tasks: what are the implications for language learning?

\begin{abstract}
Asymmetry in classroom discourse, typified by teachers' frequent use of inauthentic initiating question turns, does not afford the best opportunities for the learning of language skills. More favourable conditions would appear to be associated with collaborative discourse patterns that display genuine interest in the child's contribution and build on, and respond to, the child's turn. Video-recordings were made of consecutive episodes of 'story-writing', 'speaking book' and 'circle-time' activities to explore the sequential implications of the teachers' initiations across each task. During speaking book the teacher initiates with topic initial elicitors which invite news, ideas or opinions from the child. In story-writing the teacher employs invitations, which call for the children to generate ideas or suggestions. Analysis of teacher follow-up turns demonstrates ways in which they recast and reformulate the children's response turns and elicit further material related to the pupils' agendas. By contrast, there is limited evidence of negotiation in the circle-time activity. The study demonstrates the potentially facilitative role played by triadic dialogue in language learning and therefore has professional significance for all those involved in the development of oral language skills in classrooms.
\end{abstract}

Key words: classroom discourse, language learning, language disability Word count: 7404 


\section{Triadic dialogue in oral communication tasks: what are the implications for language learning?}

There is increasing evidence of a close relationship between early language competence and later cognitive and linguistic development. Good oral language skills are the foundation on which literacy development is based, since spoken and written language development would appear to share some of the same processes (Catts and Kamhi, 1999). More specifically, better performance in reading comprehension rests on early vocabulary knowledge (Cunningham and Stanovich, 1997) as well as verbal ability (Hatcher and Hulme, 1999). However, there is concern that on entering school many children may not have the necessary language for literacy development (Snow, 2001). Children reared in poverty, who have been shown to have depressed oral language scores, are particularly at risk (Locke et al., 2002). Longer-term academic failure is also predicted for children who have additional problems learning language, because they experience speech and language impairments (SLI), (Conti-Ramsden et al., 2002; Nathan et al., 2004). There is clearly an urgent need to provide good quality oral language experiences through the early school years and beyond that foster the development of communication and literacy skills.

The discourse processes during mainstream classroom lessons have been well documented (for overviews see Cazden, 2001; Stierer and Maybin, 1994), but may not be best suited to providing opportunities for language learning. As there are large numbers of children in classes, this lends itself to a turn-taking system in which the teacher allocates the majority of speaking turns and leads to few opportunities for children to self-select and influence the topic of the talk (Mercer, 1995). By the use 
of questions, teachers generally elicit expected information since they are the "primary knower' in terms of pedagogical knowledge (Nassaji and Wells, 2000). This pattern of discourse, widely referred to as the IRE or IRF, (and also known as triadic dialogue), is designed as a teacher initiation (I), frequently taking the form of a test or display question, which predicts a pupil response $(\mathrm{R})$ that provides the known information. The option available to the teacher in the following turn is to evaluate (E) the response in terms of its closeness to the expected answer or to provide feedback (F) (Mehan, 1985; Mercer, 1995). Of crucial importance is the sequence of turns.

Given the extensive knowledge-base about these classroom processes, as well as the availability of publications packed with ideas for altering such a pattern of dialogue (Baddeley, 1992; Dawes et al., 2000; Morgan and Saxton; 1991, Norman 1992), it might be expected that teachers would have a repertoire of different strategies. Yet there is international evidence that the IRE/F continues to be the dominant discourse style, for example in primary classrooms in the United States, Russia, India, France and England (Alexander, 2000), secondary US English lessons (Gutierrez, 1994; Nystrand et al., 1997), early years' settings (Hughes and Westgate, 1997) and during the primary literacy hour in England (Mroz et al., 2000).

More favourable conditions for oral language learning would appear to be associated with collaborative discourse patterns. Bakhtin (1986) offers a conceptual framework for interpreting the difference between teacher-dominated styles of talk versus those in which the agenda is shared between teacher and learners. Teachers adopting monological strategies dominate the talk, implying that they are in possession of the 
truth and are engaged in the instruction of others who lack it. By contrast, dialogic discourse involves a greater degree of interaction and shared responsibility for the agenda (Alexander, 2004, Skidmore, 2000). Some dialogical patterns have been found in US English lessons wherein teachers allow students to influence the development of the topic (Nystrand et al., 1997). A dialogical framework therefore invites reinterpretation of the IRE/F in terms of the information generated.

With respect to the first turn, as far as the IRF is concerned, the evidence is convincing that the design of the initiation is the key to the type of information generated and the range of possibilities in the third turn position. Although topic initiation can be achieved by turns designed in several ways, there has been a great deal of research interest in initiations designed as teacher questions because they are so prevalent. Indeed, observational studies provide evidence that when teachers ask negotiating questions children produce longer and more complex responses (Nassaji and Wells, 2000). Also, when the adult asks a question that is genuine, the child is more likely to contribute an idea or opinion and the third turn is less likely to take the form of an evaluation (Hughes and Westgate, 1998). One issue for initiation questions that foster collaboration would thus appear to be whether or not the teacher knows the answer already. What is important, moreover, is the extent to which the adult is seriously prepared to consider the child's contribution to the topic at hand (Nassaji and Wells, 2000).

The third turn has been shown to perform additional work to evaluation, leading researchers to argue for its re-interpretation. Extension affords the addition of the specialised vocabulary of the lesson (Wells, 1993). Revoicing entails repetition and 
re-formulation to give students a bigger voice (Cazden, 2001; O'Connors and Michael, 1996). High level evaluation involves elaboration of important points made by the students or exploration of a new line of thought initiated by them (Nystrand et al., 1997). However, turns such as extensions may merely confirm the unequal distribution of the stock of knowledge, in favour of teachers who operate with strong pedagogical intent.

What is needed in language classrooms is a more precise understanding of ways in which follow-up turns afford opportunities specifically for the learning of language. In this respect the notions of contingent instruction (Wood, 1998) or 'responsive assistance' (Tharp and Gallimore, 1998) may be useful. Contingency and responsiveness emphasise the continual adjustment of help and support offered by more capable others in response to the learner's performance and are particularly evident during episodes where the participants engage in meaning negotiation (Daniels, 2001). Recasts and expansions represent features of input that assist language development in young children as well as those with specific language difficulties (Nelson, 1989; Nelson et al., 1995, 1996). What is notable about these follow-up turns is that they build contingently on the child's contribution and therefore any new features to be learnt are more likely to be noticed in the teacher's input. The argument presented here is that some classroom activities may be better suited to providing third turn recast and expansion opportunities than others.

However, it is less clear how different communication tasks, that are specifically intended to develop language skills, influence these discourse patterns. Given that large class contexts are not generally conducive to language learning for children 
experiencing language difficulties, activities in dyadic situations or small group settings merit investigation. Studies concerning language learning in second language (L2) classes may offer some insights in this respect. L2 researchers who adopt an interactional perspective assume that a second language is best taught and learnt in contexts where meaning can be negotiated (Long, 1981, 1983, 1996). In the classroom the design of a group communication activity influences the flow of information between participants (Pica et al., 1993). What is crucial is the extent to which different participants during the discourse have knowledge that is needed to complete the task. This clearly raises issues about how best to elicit from a young child, or a learner with a language difficulty, information that is potentially new or interesting to the topic at hand, as opposed to pre-defined by the curriculum. The aim of the current investigation is therefore to compare and contrast a range of tasks whose goals, according to the teachers, are to develop oral language skills. These tasks will be compared along a series of interactional dimensions according to the experiences that they afford for the learning of language.

\section{Method}

Given the arguments presented above, the analysis seeks as a priority to uncover instances of collaboration, or otherwise, within the speaking and literacy lessons, paying particular attention to the design of triadic dialogue. The purpose, then, is not so much to suggest that the data are representative of teachers' interactions in oral language lessons, but to uncover patterns of possible behaviours. In other words, given similar task arrangements and discourse conditions, there exists the possibility of a teacher producing similar behaviours. 
The participants are three specialist language unit teachers who had all worked for between 10-15 years in small group settings with children experiencing speech and language impairments (SLI). These teachers conducted oral language lessons on a daily basis so had extensive experience of such activities. The children, aged $4 \mathrm{y} 4 \mathrm{~m}$ to $8 \mathrm{y} 7 \mathrm{~m}$, had moderate to severe receptive and expressive language difficulties such that they required full-time placement in a specialist language provision and received regular speech and language therapy. All names used in the text are pseudonyms to protect the confidentiality of the participants.

Three types of communication task are compared in the current analysis, the first called 'speaking-book', next involving writing a story, and thirdly a small group circle-time. Speaking book is a context for talk that is conducted on an individual basis. The adult and child share a visual resource in the form of a book into which pictures have been stuck, selected mainly by the child. The pair typically discuss one picture at a time, each page representing a potentially different topic for talk, so a session will cover several pictures. Story-writing is a daily activity characterised by a group of 5-7 children sitting in an arc in front of the teacher. It follows a predictable routine whereby the teacher invites the pupils to make suggestions about the characters, settings and events of a story and uses a flipchart to visually represent their ideas. Circle-time includes 5-6 children seated in a ring on the floor. The teacher holds a conch shell while she speaks and passes this to the next person so that they can take a speaking turn following the teacher's initial model. Each lesson was videotaped either as a group or dyad on four separate occasions, creating a database of 
sixteen lessons. The teachers were interviewed following each lesson about their goals for that activity in relation to the children's language learning needs.

Analytical framework

The analytical approach is informed by the principles of conversation analysis (CA), suited to the current investigation because of the primary concern with sequentiality. Conversation analysts have extensively studied ways in which topic is generated in mundane, social conversation. Owing to the potentially social concerns of oral language teaching, as opposed to lessons concerned with the transmission of curriculum knowledge, topic generation provides a contrastive perspective on what is known about institutional triadic dialogue. Three devices to generate topic are relevant to the current paper, outlined in Table 1. The examples given are from a study by Radford and Tarplee (2000) whose methods were informed by accounts of 'news' generation in conversation by Button and Casey $(1984,1985)$.

Place Table 1 near here

The first option is an itemized enquiry (IE) which is a query aimed at a particular item of news (e.g. what happened in maths). As the speaker is electing to nominate topical material, knowledge of what is newsworthy and worthy of being shared is necessary. Production of this opener invites the recipient to tell things about the newsworthy item, rather than simply filling a gap in the speaker's knowledge. It falls to the 
speaker in the third turn position to topicalize the material generated by the itemized request, for example by an encouraging ' $\mathrm{mm}$ hh' that serves to invite the recipient to 'tell more' about their news. The next option to open topic for talk is called a topic initial elicitor (TIE), characterized by an open enquiry directed at the possible activities of the conversational participant (e.g. what happened at the week-end). The noteworthy feature of a TIE is that it carries no specific topical material itself, but serves to invite the speaker in the subsequent turn to provide a report of events that are newsworthy. The first speaker is displaying availability for talk, to which the second speaker responds with a possible initial topic (e.g. going to the presentation evening). In the third turn position, then, the first speaker has the obligation to topicalize the news received to display availability to talk about that topic. Thirdly, a speaker may initiate with topical material directly, by making a news announcement (e.g. going to Tanzania), projecting more to tell in subsequent turns. Topicalization then occurs in the second turn position - and we see here a prototypical example ('Did you?') - that invites elaboration of the news. For the purposes of the current analysis the crucial dimensions are the openness of the TIE as contrasted with the nature of the topical material nominated within an IE.

The analysis of the current data is set out as follows:

First the turn-taking system is examined for ways in which speaking rights are allocated and the extent to which speakers are free to elect to speak. Next, details concerning the design of the triadic dialogue are presented, contrasting the effects across the three communication tasks. The work of the teachers' initiation is interpreted in terms of the information generated and the implications for the various options in the follow-up turn position. These interactional data are discussed in terms 
of the teachers' goals for the given communication task. Reference will be made to extracts from the data.

\section{Analysis}

Turn-taking

Turn-taking is controlled by the teachers during both the speaking and story-writing tasks since they consistently nominate the next speakers either directly by name or by looking at them. Nonetheless, there is evidence that children on occasion do selfselect by volunteering further topical material without direct invitation. This may be contrasted with a different arrangement during circle-time where the turn-taking system is pre-set and the routine nature of this activity predicts that speakers only have rights when they hold the shell. Even the young four-year-olds with language difficulties conformed to this unwritten rule. Such a system has the effect of reducing the proportion of teacher turns.

Triadic dialogue

The teachers in all three task types ask many questions in the first turn of the triadic dialogue. Examples are 'Wh' interrogatives like 'Where is he going?', polar interrogatives such as 'Can you write it down?' or tag questions like 'She can't write, can she?' (see Figure 1). The distribution in Figure 1 is of interest: teachers use a

Place Figure 1 near here 
total of 349 questions in the speaking and story lessons but only one during circletime. Whilst it is recognised that the length of a session might influence the number

of questions asked, the topical analysis will later confirm that the pattern suggested in figure 1 is an artefact of the way in which the teacher generates topic in circle-time. So far then, in terms of turn-taking and question use the analysis would appear to suggest a dominant teacher style for speaking book and story writing and a freer situation during circle-time. However, when initiations as a whole are examined within their sequential contexts, including alternatives to questions, a different picture emerges.

\section{Topic generation in the speaking book task}

During the speaking book task the teacher employs topic initial elicitors (TIEs) in the initiation slot to generate topic (see line 4 in extract 1; line 2 in extract 2). These are located within the sequence of talk at the point when a new picture, for instance a photograph of the child herself, is the joint focus of attention. The use of the opener (line 1 extract 1) constrains the child to talk about the picture. The open design of line 4 extract 1 does not in itself nominate topical material. This feature is consistent even when the syntactic design is an interrogative (extract 3, line 1). Like TIEs in social talk, the broad design allows volunteering or choice of what news, story or observation to tell and projects several options for topical pursuit. Use of 'all' in 'what's this all about' (line 1 extract 3 ) further indicates the breadth of possibilities. 
Extract 1 ( $\mathrm{T}=$ teacher, $\mathrm{P}=$ pupil)

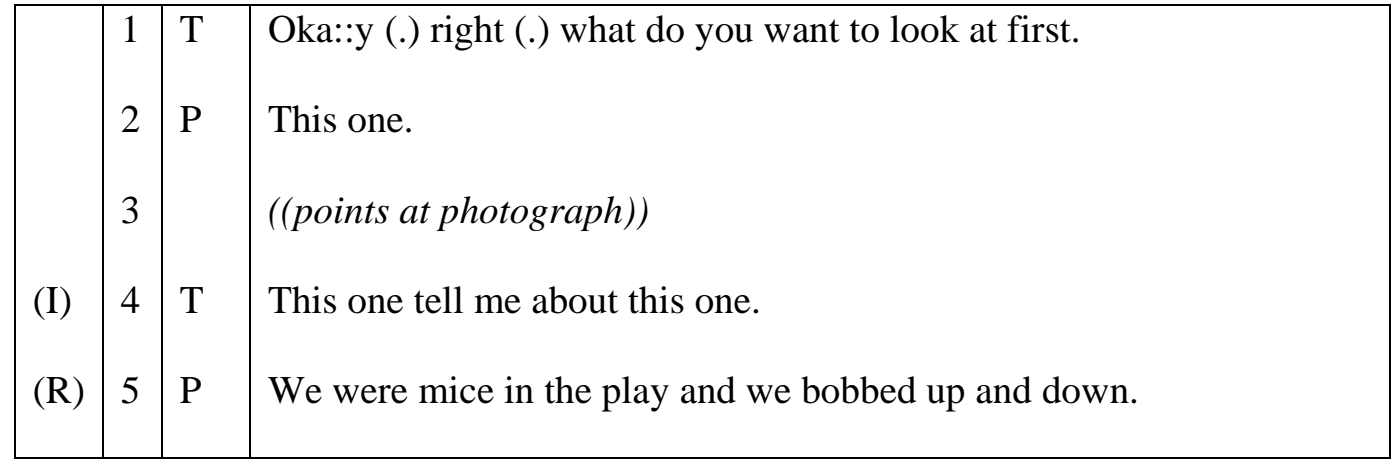

Extract 2

\begin{tabular}{|l|l|l|l|}
\hline & 1 & $\mathrm{~T}$ & Right what other pictures I haven't seen these pictures either. (.) \\
(I) & 2 & & Tell me about those. \\
(R) & 3 & $\mathrm{P}$ & Uhh there's a kitten and she's looking for mice. \\
(F) & 4 & $\mathrm{~T}$ & Mm hh \\
& 5 & & $(0.5)$ \\
& 6 & $\mathrm{P}$ & And when he eat the mice he gonna die. \\
\hline
\end{tabular}

\section{Extract 3}

\begin{tabular}{|l|l|l|l|}
\hline (I) & 1 & $\mathrm{~T}$ & Right oh I haven't seen this picture. What's this all about. \\
(R) & 2 & $\mathrm{P}$ & Scissors a pencil sharpener a clip. \\
\hline
\end{tabular}

\section{Extract 4}

\begin{tabular}{|l|l|l|l|}
\hline (I) & 1 & $\mathrm{~T}$ & Tell me about this one. \\
(R) & 2 & $\mathrm{P}$ & Uhh there's a girl (.) and she's crying (.) because (.) her brother is \\
& 3 & & killed. \\
(F) & 4 & $\mathrm{~T}$ & Can you tell me about the girl... \\
\hline
\end{tabular}


Initiating the topic using Topic initial elicitors (TIE) and responses (R)

The teacher's use of TIEs succeeds in generating information in the response turn position as evidenced by the children's production of material related to the pictures. The nature of the picture determines the content of the response: the preferred response to photographs is a telling of the news about "what happened in the school play' in extract 1. By contrast magazine pictures and line drawings lend themselves to description (extracts 2, 3 and 4). However, there is simultaneously the potential for elaboration beyond the literal content of the drawing ('because her brother is killed' in extract 4). Whilst use of 'Uhh' in extracts 2 and 4 implies the child is searching for information, there is nonetheless free volunteering of material, since she offers two clauses in extracts 1 and 2 and three clauses in extract 4 . These several items of information project either 'more to tell' by the child or function as potential resources for the teacher to pursue topic.

The follow-up turn (F)

As in social talk, having used a TIE, the teacher has a sequential obligation in the follow-up turn position to topicalize the information in order to invite the pupil to continue the topic she has offered as a potential subject for joint consideration. One option at this point is for the teacher to produce a phatic such as 'mm' or 'mm hh' (line 4, extract 2). The advantage of a phatic in third turn position is that it is empty of content whilst having the sequential effect of the child producing further topical material in the subsequent turn (line 6 extract 2). The pause in extract 2 (line 5) is also notable in this regard because it provides a slot in which the pupil can add additional information to the topic generated in the response turn. In this sense the pause suggests that the teacher holds an expectation of more information to follow. 
This situation contrasts with repeated production of IRF where the alternative would have been for the teacher to ask a further question.

The most common device used to pursue topic in turns following a child response is an itemized enquiry (IE) (see extract 4 line 4, extract 5 lines 2 and 4 and extract 6 line 3). These enquiries contrast with the empty design of the teacher's initiations, the important difference being that they nominate the topical agenda that will be jointly pursued. Whilst the teacher makes various choices about what to nominate as worthy for topical pursuit, what is consistent is that she orients to the agenda first initiated by the child in the response turn rather than nominating a new line of enquiry.

More about itemized enquiries in the follow-up turn

Itemized enquiry designs fall into two categories: broad and specific.

Specific IEs: As seen in extract 4 above (line 4), a specific IE nominates an element of the response turn for elaboration (in this case 'the girl'). In extract 5 line 2 , there is reference in the IE to people and experiences known to the child but not shared yet, according to the available evidence, with the teacher. It is notable that, in terms of question design, the teacher produces both a polar (extract 5 line 2) and a 'Wh-' interrogative (extract 5 line 4). Both are structures that potentially constrain what can be selected by the subsequent speaker. However, collaboration is increased through the teacher's appeal to the pupil's superior knowledge about her family, as evidenced in the child offering new information about her father (extract 5 line 5). This renders the teacher's turn not only an enquiry that is itemized to elicit material related to a nominated topic, but also personally oriented to the child's agenda. 


\section{Itemized enquiries (F)}

Extract 5 (specific IE)

\begin{tabular}{|l|l|l|l|}
\hline (R) & 1 & $\mathrm{P}$ & Alex stayed at home \\
(F) & 2 & $\mathrm{~T}$ & Did Steven hold the dog as well? \\
& 3 & $\mathrm{P}$ & $(($ nods $))$ \\
(F) & 4 & $\mathrm{~T}$ & Yeah? What about dad he didn't go? \\
& 5 & $\mathrm{P}$ & No he didn't go cos he was (.) cos he can't leave Alex on his own. \\
\hline
\end{tabular}

Broad IEs: By contrast, although they nominate the topic, broad itemized enquiries predict a variety of choices for topical development in later turns. They are typically designed as open questions. For example ‘what else..' (extract 6, line 3) projects a range of options relating to the nominated topic of the girl. 'What happened..'

(extract 7, line 4) lends itself to the potential to extend knowledge of an event experienced directly by the child, seen here in the production of an event report in the subsequent turn. A further broad design is 'I wonder if...' (extract 8, line 1) used in this case to pursue the topic about a man who does not have enough money. As a modality this verb projects imaginative possibilities and has the effect of an extended turn from the pupil started similarly with the modalisation 'I think'.

Extract 6 (broad IE)

\begin{tabular}{|l|l|l|l|}
\hline & 1 & $\mathrm{~T}$ & Is she a big girl or little girl? \\
(R) & 2 & $\mathrm{P}$ & Uhh big girl. \\
(F) & 3 & $\mathrm{~T}$ & Uhh what else can you tell me about her? \\
& 4 & $\mathrm{P}$ & Uhh she has hair... \\
\hline
\end{tabular}


Extract 7 (broad IE)

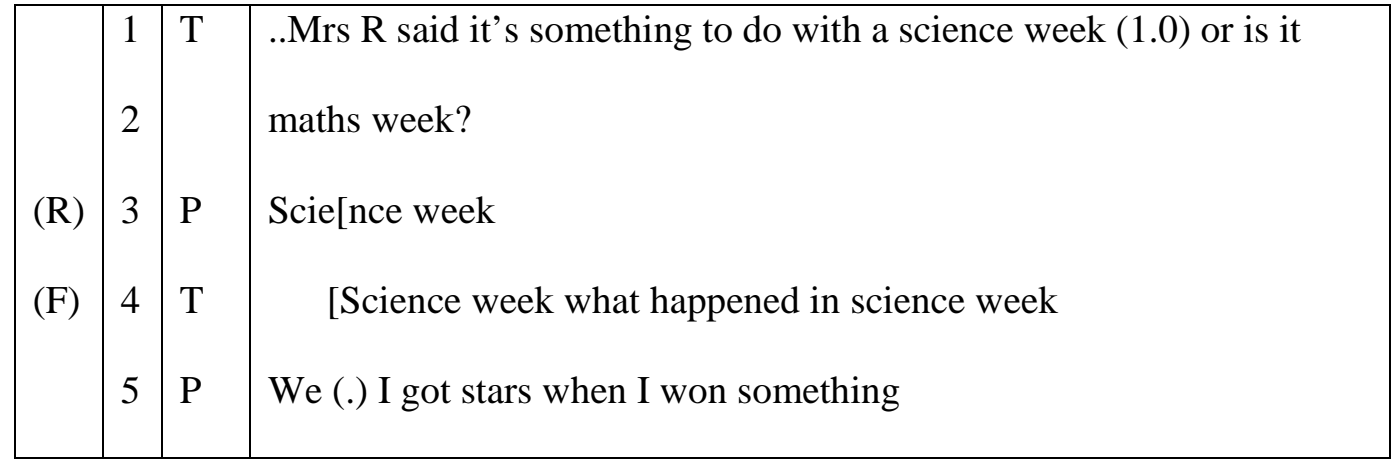

Extract 8 (broad IE)

\begin{tabular}{|c|c|c|c|}
\hline (F) & 1 & $\mathrm{~T}$ & $\begin{array}{l}. . \text { I wonder what he can do about it I wonder if he can make her } \\
\text { change her mind } \\
\text { (1.0) } \\
\text { I think the girl go home and say (.) } * * * \text { earn some money she'll make } \\
\text { a joke }\end{array}$ \\
\hline
\end{tabular}

Topic generation in the story writing task

The general pattern of topic initiation during story-writing is one of the teacher soliciting ideas from the pupils according to a broad script that is outlined in Table 2. The order and components of the script are adhered to in all recorded sessions, and relate to decisions about how to open the story, the character (s), setting, plot, ending and title. The work of these initiations may be summarised as topic invitation and its sequential effects are illustrated below in terms of the generation of character and plot ideas.

Place Table 2 near here 
Character suggestions are typically invited by the teacher using an oral cloze design (extract 9, lines 1 and 2). In the first line she nominates the speaker to make the character selection by looking and naming him ('Eddie'), and then she repeats the start of the story, as just decided by another pupil ('one day'). Next, she begins a sentence syntactically designed as a character introduction, such as in a traditional fairy tale ('there was a'). At this point she pauses whilst gesturing with her hands forward to the next speaker she has nominated. Eddie (E) suggests a character for the story, providing a noun ('boy') as well as a description ('little') which the teacher fully accepts with both repetition of the child's turn and subsequent incorporation into an introductory sentence for the story (line 5: 'one day there was a little boy').

Extract 9 Showing character invitation, response(s) and acceptance

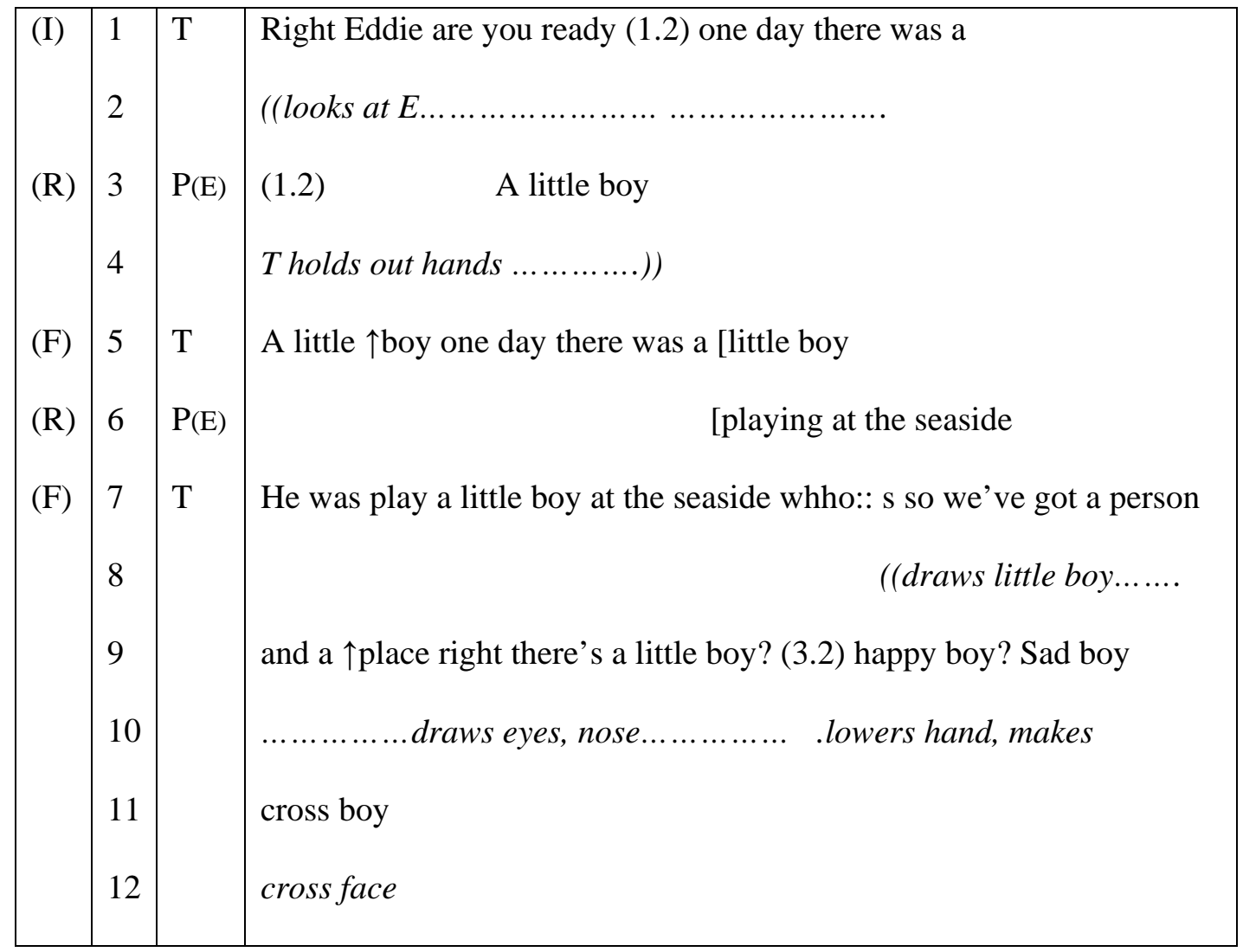




\begin{tabular}{|l|l|l|l|}
\hline 13 & $\mathrm{P}(\mathrm{D})$ & Sad boy **** \\
14 & $\mathrm{~T}$ & Wait a minute (.) wait a minute (.) sad boy okay (.) and we' re at the \\
15 & & \multicolumn{1}{|c|}{$(($ draws sad mouth, takes } \\
16 & & $\begin{array}{l}\text { seaside (0.7) okay (.) right (0.5) sand what else do we need at the } \\
17\end{array}$ \\
18 & & $\begin{array}{l}\text { yellow pen, draws sand ..........)) } \\
\text { seaside }\end{array}$ \\
\hline
\end{tabular}

Selection of the story setting is invited on most occasions by 'Wh' interrogatives. In the first turn of extract 10 (line 1) the teacher retells the story, as already jointly agreed, in terms of the introductory opener and character. Her 'Wh' interrogative is an itemized enquiry that elicits a relevant setting in relation to the character chosen, as far as the verb 'live' reasonably applies to cheetahs. Pupil Anna's (A) response (line 3: 'in a house') is greeted with a confirmation check, which, when confirmed, is repeated by the teacher. At this point, the invitation sequence could have been completed, since it has generated the necessary choice of setting. However, Anna elects at this point to volunteer additional information about the number of the house (line 7: 'forty four'). The teacher could have chosen not to accept the unsolicited suggestion, but there is clear evidence that she does so, by incorporating it into the description ('a house called forty four'), as well as representing Anna's ideas in her drawings. The flipchart thus becomes an arena for confirming the joint decisions made, as suggested by the child and accepted by the teacher. 
Extract 10 Setting invitation, response(s) and acceptance

\begin{tabular}{|c|c|c|c|}
\hline \multirow[t]{2}{*}{ (I) } & 1 & $\mathrm{~T}$ & $\begin{array}{ll}\text { One day }(0.2) \text { there was a cheetah }(0.4) \text { where }(.) \text { does it live }\end{array}$ \\
\hline & 2 & & ((looks at Anna...palms up $))$ \\
\hline \multirow[t]{3}{*}{$(\mathrm{R})$} & 3 & $\mathrm{P}(\mathrm{A})$ & In a house \\
\hline & 4 & $\mathrm{~T}$ & In a house \\
\hline & 5 & $\mathrm{P}(\mathrm{A})$ & $(($ nods $))$ \\
\hline (F) & 6 & $\mathrm{~T}$ & Cheetah lives in a house \\
\hline$(\mathrm{R})$ & 7 & $\mathrm{P}(\mathrm{A})$ & Forty four \\
\hline \multirow[t]{4}{*}{$(\mathrm{F})$} & 8 & $\mathrm{~T}$ & A house called forty four (.) okay (.) here comes the house (.) One \\
\hline & 9 & & ((takes pen........draws the house......... \\
\hline & 10 & & day there was a cheetah (.) lived in a house (.) number (.) forty four \\
\hline & 11 & & .................draws roof and door.......................writes 44)) \\
\hline
\end{tabular}

Similar to setting elicitation, plot invitations are designed as itemized enquiries that take the syntactic form of 'Wh' interrogatives. We find three examples of this feature in extract 11 (lines 2, 10 and 14), the first appearing in the sequential position following the child's retelling of the story. Since the invitation is designed with the verb 'do' it predicts an action-type plot from pupil Dina (D). However, as it is a general verb, it leaves plenty of semantic scope for the child's choice of activity. Given that Dina selects a plot concerning a fight, the teacher has the job of interpreting this as a manageable story-line. Her subsequent 'Wh' questions invite elaboration from Dina of how this scenario is played out, in a form that she is able to represent on the flipchart. 
Extract 11 Plot invitation

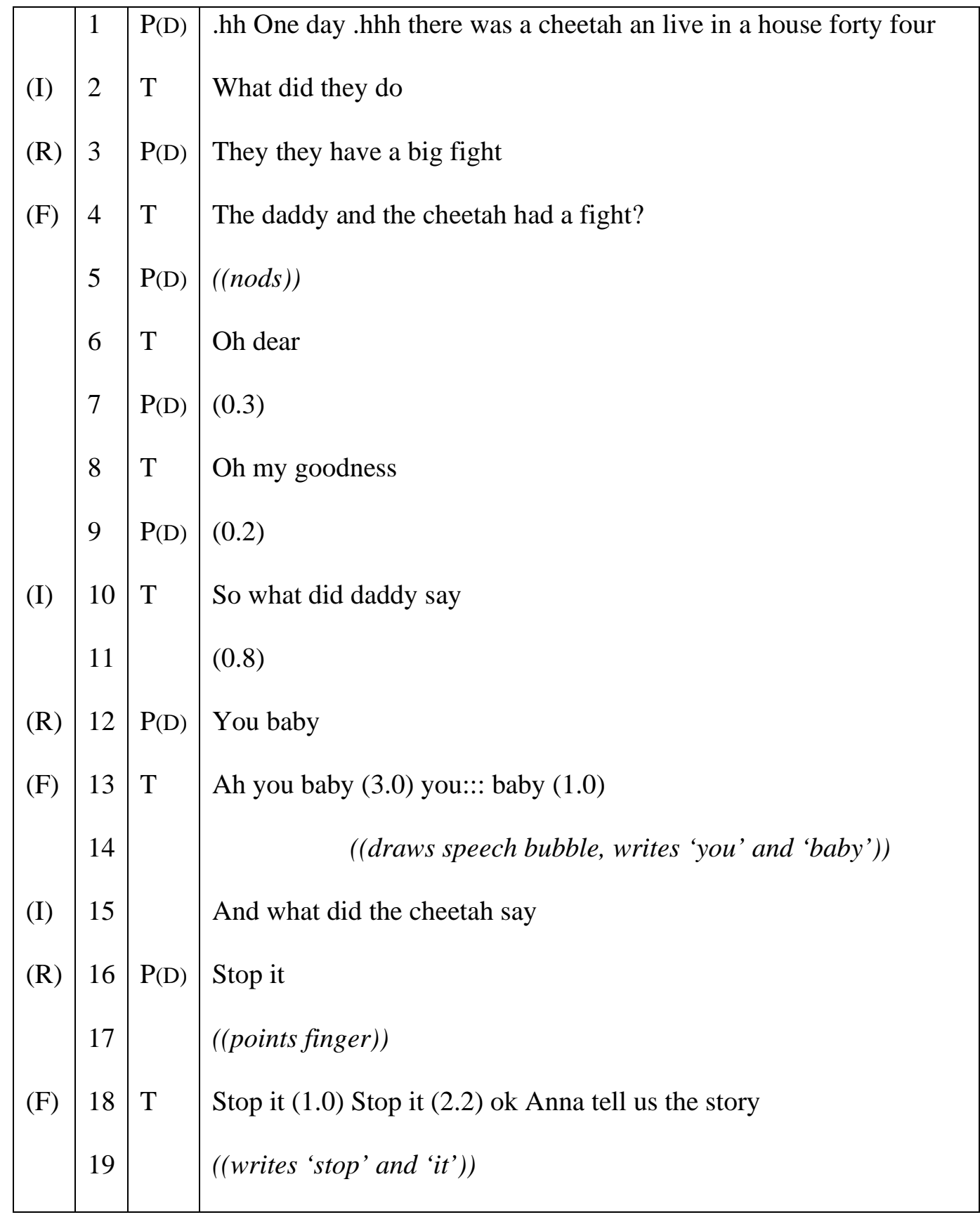

Extract 12 begins with a three part sequence that is typical of the story invitation system encountered in this activity type. First, the teacher invites a description from pupil Laurence (L) to assist her drawing of the story's character, a cheetah. The description is formulated in the response turn and provides key pieces of information 
('a body and four legs'). The teacher commences an acceptance in the follow-up turn position ('right okay') but is interrupted by the child who treats her repetition as a partial, and therefore incomplete, description of a cheetah. Laurence thus offers a further character feature ('face') and, when this is repeated by the teacher, offers another one ('spots on'). The collaboration about character features could therefore be said to be led by the pupil. In many classroom contexts a child interruption would not be an appropriate next turn, but there is evidence here not only of its appropriacy (it is repeated by the teacher), but that it is welcomed ('that's really helpful'). Indeed the teacher proceeds to incorporate all of the child's ideas into the final acceptance slot (lines 7-9).

Extract 12 Ideas volunteered

\begin{tabular}{|l|l|l|l|}
\hline (I) & 1 & $\mathrm{~T}$ & I think you need to tell us what a cheetah is it's like a tiger \\
(R) & 2 & $\mathrm{P}(\mathrm{L})$ & It's got a body and four legs \\
(F) & 3 & $\mathrm{~T}$ & It's got a body and four legs [right okay \\
(R) & 4 & $\mathrm{P}(\mathrm{L})$ & [and face \\
(F) & 5 & $\mathrm{~T}$ & and a face \\
(R) & 6 & $\mathrm{P}(\mathrm{L})$ & spots on \\
(F) & 7 & $\mathrm{~T}$ & A face with spots on that's really helpful (.) right there's a body...etc \\
& 8 & & ((draws a body and proceeds to draw 4 legs, face, whiskers, eyes, \\
& 9 & & mouth, tail and spots) ) \\
\hline
\end{tabular}

When analysed more closely it is apparent that the follow-up turns in these extracts achieve a range of different work. In lines $13 \& 14$ and lines $18 \& 19$ of extract 11 
they function as acceptances in a similar fashion to that illustrated earlier. In contrast, earlier in line 4 extract 11 , owing to the fact that a new idea has been generated, the teacher finds herself in a position to receive an unexpected suggestion. This results in a clarification request that, until the plot proposal has been confirmed in line 5, puts a hold on the acceptance. What is notable about the confirmation check here is that it provides a recast of the child's inaccurate rendering of the past tense of the verb 'have'. Different work again is achieved by the follow-up turn in extract 10 , line 6 : having generated ideas about the house there are two revoicings where the teacher reworks the syntax of the previous turns ('cheetah lives in a house' and 'a house called forty four'). Similarly, the final follow-up turn in extract 12 line 7 is useful. It provides supportive feedback to the pupil about his ideas, and its design, as a summary of Laurence's suggestions, recasts and expands his turns in the form of a syntactically more complex postmodified noun phrase ('with spots on'). By building on the child's choice of lexis, the follow-up turn provides a contingent opportunity for positive evidence of such a structure.

\section{Topic generation in circle-time}

Topic initiation in circle-time commences with a naming activity whereby teacher Jane presents a syntactic model of the sentence (extract 13). She passes the shell to the child Sue (S) sitting on her left. On receipt of the shell, Sue repeats the model of the sentence, whilst substituting her own name. Children's response turns continue around the circle in this fashion without prompting or interruption from the teacher. 
Extract 13 Topic initiation models and responses

\begin{tabular}{|l|l|l|l|}
\hline (I) & 1 & $\mathrm{~T}$ & $\begin{array}{l}\text { My name is Jane } \\
((\text { holds shell, passes to Sue }))\end{array}$ \\
(R) & 3 & $\mathrm{P}(\mathrm{S})$ & $\begin{array}{l}\text { My name is (.) Sue } \\
((\text { takes shell,.... passes to James }))\end{array}$ \\
(R) & 5 & $\mathrm{P}(\mathrm{J})$ & \begin{tabular}{l} 
My name is (.) James \\
\hline
\end{tabular} \\
\hline
\end{tabular}

\section{Extract 14}

\begin{tabular}{|c|c|c|c|}
\hline (I) & 1 & $\mathrm{~T}$ & I like eating apples \\
\hline & 2 & & ((holds shell, passes to Sue )) \\
\hline$(\mathrm{R})$ & 3 & $\mathrm{P}(\mathrm{S})$ & $\begin{array}{l}\text { I eat orange (.) smell orange } \\
((\text { takes shell,.... passes to James }))\end{array}$ \\
\hline$(\mathrm{R})$ & 5 & $\mathrm{P}(\mathrm{J})$ & I like eating (2.2) \\
\hline
\end{tabular}

\section{Extract 15}

\begin{tabular}{|l|l|l|l|}
\hline$(\mathrm{I})$ & 1 & $\mathrm{~T}$ & Today I feel (.) happy \\
$(\mathrm{R})$ & 2 & $\mathrm{P}(\mathrm{S})$ & Happy \\
$(\mathrm{R})$ & 3 & $\mathrm{~J}$ & $\mathrm{I}(10.00) \mathrm{sad}(0.8) \mathrm{sad}$ \\
\hline
\end{tabular}

Extracts 14 and 15 illustrate later examples of the initiation model during the circletime activity whereby the teacher nominates her favourite food (14) or the current state of her feelings (15) as the topic for the round. In the children's response turns there is evidence of orientation to the teacher's proposed initial topic through production of relevant next ideas. A notable feature is the allowance of generous 
pause, ten seconds in extract 15 which confirms the teacher's goal to give the children space to volunteer their ideas.

In extract 13, when the teacher uses a simple name model, the children's response turns represent accurate renderings of the syntax of the topic initiation. Yet for obvious reasons, owing to the nature of the children's language difficulties, such a consequence cannot be guaranteed. Extract 16 illustrates a reduced response turn following the initiation, in which Sue produces her own version of the teacher's model. She retains the teacher's central meaning but alters the syntax and semantics of her turn. Even greater discrepancy between the teacher's model and the child's turn occurs when the syntax within the initiation involves a complex embedded structure that is harder for the child to process and reproduce. Whereas in extract 14 Sue is able to formulate SVO, it is apparently beyond her production capacity to repeat the embedded structure and create 'I like eating oranges'. Given that the topic at hand would appear to be 'what we like to eat' rather than merely 'what we eat', it is unclear whether Sue is changing the meaning by failing to orient to the verb 'like'.

Extract 16 Reduced next turn

\begin{tabular}{|l|l|l|l|}
\hline (I) & 1 & $\mathrm{~T}$ & My name is Jane \\
(R) & 2 & $\mathrm{P}(\mathrm{S})$ & I'm uhh (.) Sue \\
\hline
\end{tabular}

It will now be obvious that the turn-taking system operating in circle-time affords no opportunity for follow-up work. The current speaker is required to hand over the speaking rights to the person sitting to the left by passing the shell. As can be seen in extract 17 , this means that there is no allocated speaking turn for the teacher to 
negotiate the meaning of the child's unclear contribution by initiating a repair. The absence of repair at this stage could have the sequential implication, in terms of topic, of shifting the agenda for the next speaker in the circle. Also noteworthy is that the form of the child's turn has important implications in terms of the accuracy of the syntactic model available for the next child.

\section{Extract 17}

\begin{tabular}{|c|c|c|c|}
\hline (I) & 1 & $\mathrm{~T}$ & I've got a friend (0.7) I've got a lovely friend called V ((passes shell) \\
\hline$(\mathrm{R})$ & 2 & $\mathrm{P}(\mathrm{J})$ & I like my sister (1.3) yes (1.0) fine (0.4) thank you \\
\hline & 3 & & $(($ takes shell and puts to ear................................... . . passes to $S))$ \\
\hline$(\mathrm{R})$ & 4 & $\mathrm{P}(\mathrm{S})$ & I got sister too \\
\hline & 5 & & $(($ takes shell..............passes to teacher $))$ \\
\hline & 6 & $\mathrm{~T}$ & ((takes shell)) Thank you \\
\hline
\end{tabular}

\section{Summary}

As has been demonstrated, there are important differences between the three activities in terms of the opportunities afforded for meaning negotiation. By way of summary, Table 3 compares the various dimensions that reflect mutuality, information exchange and responsive assistance in the follow-up turn.

Place Table 3 near here 


\section{Discussion}

Using CA has shown that topic is collaboratively constructed during institutional triadic dialogue in both the speaking-book and story-writing lessons, whilst coconstruction of topic is evident during the initiation and response turns of circle-time. What makes these oral language tasks different from most mainstream lessons is that the teachers' purpose is not on the accurate transmission of curricular knowledge. As a result, the questions asked are not test or display questions, since the teachers are not already in possession of correct responses and are willing to accept more than one possible answer.

The topic initial elicitor (TIE) found frequently during the speaking book activity clearly has collaborative potential. A TIE is suited to collaborative topic generation because it does not in itself nominate topical material to talk to, but orients to the potential knowledge, news or opinions of the conversational participant in the next turn (Button and Casey, 1984; Radford and Tarplee, 2000). Indeed it is the open design of the TIE, used by the teacher in the context of her willingness to listen to the material thus generated that marks it as different from a test question / known-answer initiation. In contrast, the data show that news announcements or itemized enquiries are not used in topic initiating positions. Since such designs are suited to first turn nomination of topical material (Button \& Casey, 1984, 1985; Radford and Tarplee, 2000), their usage would indicate teacher domination of the topical agenda, so their absence is a sign of her openness. Through a TIE, the teacher hands responsibility to the child to decide what is newsworthy or to select an observation related to the general topic of the book or the picture. In this respect the child is allocated the role 
of expert, or primary knower (Nassaji and Wells, 2000). It is in this way that language learning can be promoted.

A further initiation with cooperative promise is the invitation from story-writing. Indeed, while many polar and Wh interrogatives are found in this discourse position, rather than constrain the child's options, the turn functions as a summons to select components of the story. As such, invitations provide creative opportunities in the response turn to offer imaginative suggestions within the structure of the storybuilding framework. There is notable free selection in relation to the choice of characters, setting and plot and the ideas generated are a necessary resource for the group to produce the joint outcome of a story. This fits the optimal conditions for group communication tasks since each interactant holds a portion of the information needed to achieve the activity's goal (Pica et al., 1993).

The pattern of topic generation in circle-time is organised in two parts: first the teacher's topic model, followed by a chaining of pupils' next turn responses. On a positive note, the model does succeed in generating personal contributions and therefore fulfils the teacher's goals for the pupils to generate ideas whilst allowing them the freedom to remain silent if they so wish, as there is no obligation to supply information. Furthermore, this turn-taking system ensures that pupils are free from interruption from others who could steal a turn while they take the time to formulate a response.

However, as far as language learning opportunities are concerned, the circle-time scheme warrants interpretation in terms of the possibilities for positive evidence, 
topical pursuit and responsive assistance. The teacher's first turn provides an appropriate syntactic and semantic model for the children to copy and some do succeed in producing next turns that fulfil the expectation. On the other hand, the fact that the turn-taking system demands that each pupil takes a turn leads to a crucial time lag between her model and some of the children's turns, a potential problem for children with language difficulties. The child also runs the risk of being presented with a syntactic model that is inaccurate from the previous child's turn. Furthermore, if the child's language learning goals concern syntax, the absence of follow-up turns denies the teacher a next turn slot in which to provide a recast or reformulation. Another concern is that, on occasions when the meaning of the child's turn is unclear, there is no opportunity to initiate a content repair in order to clarify the meaning. This calls for clarity in the setting of teaching objectives for the circle-time lesson.

As for follow-up turns in the speaking and story tasks, there is acknowledgement by the teacher of the subject matter of the child's response. In this sense, the third turn functions similarly to high level evaluations (Nystrand et al., 1997). Yet this analysis has uncovered further features of interest for the purposes of language learning. First, itemized enquiries in the speaking task are often socially oriented, especially when they refer to the child's personal news accounts. The interview data confirmed that the teacher's goal was to do 'social talk' addressed to the child's agenda which was why photographs were used. In contrast, an acceptance in the story writing activity is cognitively oriented in so far as it does the job of welcoming the child's contribution to the developing story, even expressing praise regarding its relevance. 
Paraphrase of a response turn is a common technique used by teachers to filter out an invalid contribution so that it is redefined towards an intended plan or known answer (Edwards and Mercer, 1994). A different picture emerges in these data because when the teachers recast or reformulate the children's turns, they orient to the new knowledge created. As they are not sieving out the bits that do not conform to a preconceived plan, they are not attempting to validate their authority over the knowledge and understandings generated. Rather, as Cazden (2001) has observed, revoicings treat children as continuing negotiators about their ideas and even afford them the right to challenge the teacher's interpretation. Importantly, also, as far as language learning is concerned, recasts and reformulations provide positive evidence of the syntax and/or semantics of the child's previous turns. As Ridley, Radford and Mahon (2002) also found in teacher and peer interaction, the follow-up turn affords contingent opportunities for additional syntactic and semantic elements to be added. Whether or not such models are noticed as input by the child, of course, certainly requires further investigation

\section{Conclusion}

This research has identified the potentially facilitative role played by triadic dialogue in language learning. The data show collaborative zones of negotiation in topical development during the speaking and story-writing activities. These zones can be instantiated as the sequences of IRF turns where the teacher and the pupil are negotiating the topical content. These sequences relate to Vygotsky's notion of the zone of proximal development (Vygotsky, 1962) in so far as such sequential contexts provide opportunities for contingent talk by a more capable other that is pitched 
beyond the child's current level of language development. Thus zones of negotiation can provide favourable conditions for language learning in terms of the dimensions discussed at the beginning of the paper: the active engagement of the child, an interest in the exchange of ideas (dialogism), and responsiveness to the pupils' agenda. They may also occur when it is the child, rather than the adult, who is more knowledgeable about the topic.

Our findings show that, in contrast with previous research on teachers' use of questions, under certain conditions questions can do collaborative work. These appear to be: first, that the speaking turn system of the activity permits pupil selfselection and teacher follow-up; next, that initiations invite or elicit pupils' personal news, ideas or opinions; finally that, from these contexts, follow-up turns can do the business of accepting, incorporating, reformulating and extending pupil's responses. Indeed, even young children experiencing specific language difficulties have no shortage of ideas when encouraged to present them within a structured framework. Moreover, small group activities are not disadvantaged as compared to dyadic tasks, in so far as similar phenomena are found in both contexts.

What is clear is that, in small group communication tasks, there exists a very close relationship between the lesson context and the design of the triadic dialogue. Within an interactionist perspective on language learning, the study has professional implications for both teachers and speech and language therapists who support the oral language skills of all young children, not just those who experience specific language difficulties. These professionals may find the dimensions summarised in 
Table 3 a helpful frame of reference to assist the interpretation of communication tasks in terms of their language learning opportunities in classrooms.

References

Alexander, R.J. (2000) Culture and pedagogy: International Comparisons in Primary Education. Oxford: Blackwell.

Alexander, R.J. (2004) Towards Dialogic Teaching: Rethinking Classroom Talk. (2 ${ }^{\text {nd }}$ edn.) Dialogos: University of Cambridge.

Baddeley, G. (1992) Learning Together Through Talk: Multimedia Key Stage 1 and 2. London: Hodder and Stoughton.

Bakhtin, M. M. (1986) Speech Genres and Other Late Essays. (Y. McGee trans.) Austin: University of Texas Press.

Button, G. and Casey, N. (1984) Generating Topic: the use of topic initial elicitors. In J.M. Atkinson and J. Heritage (eds.) Structures of Social Action: Studies in Conversation Analysis. Cambridge: Cambridge University Press.

Button, G. and Casey, N. (1985) Topic Nomination and Topic Pursuit. Human Studies 8, 3-55.

Catts, W.W. and Kamhi, A.J. (1999) Language and Learning Disabilities. London: 
Allyn and Bacon.

Cazden, C.B. (2001) Classroom Discourse: The Language of Teaching and Learning. ( $2^{\text {nd }}$. edn.), Portsmouth: Heinemann.

Conti-Ramsden, G., Knox, E., Bottong, N. and Simkin, Z. (2002) Educational placements and key stage 2 test outcomes of children with a history of specific language impairment. British Journal of Special Education 29 (2), 76-82.

Cunningham, A. E. and Stanovich, K. E. (1997) Early reading acquisition and its relation to reading experience and ability ten years later. Developmental Psychology $33(6), 934-945$.

Daniels, H. (2001) Vygotsky and Pedagogy. London: Routledge.

Dawes, L., Mercer, N. and Wegerif, R. (2000) Thinking Together: A programme of activities for developing thinking skills at KS2. Birmingham: Questions Publishing Company.

Edwards, A.D. and Westgate, D.P.G. (1994) Investigating Classroom Talk. (2 ${ }^{\text {nd }}$ edn.). London: Falmer Press.

Gutierrez, K.D. (1994) How Talk, Context and Script Shape Contexts for Learning: A cross-case comparison of journal sharing. Linguistics and Education 5, 335-65. 
Hatcher, P.J. and Hulme, C. (1999) Phonemes, rhymes and intelligence as predictors of children's responsiveness to remedial reading instruction: evidence from a longitudinal intervention study. Journal of Experimental Child Psychology 72, 130153.

Hughes, M. and Westgate, D. (1997) Assistants as Talk-partners in Early Years Classrooms: some issues of support and development. Educational Review 49 (1), 512.

Hughes, M. and Westgate, D. (1998) Possible Enabling Strategies in Teacher-led Talk with Young Pupils. Language and Education 12 (3), 174-91.

Hutchby, I. and Wooffitt, R. (1999) Conversation Analysis: Principles, Practices and Applications. Cambridge: Polity Press.

Locke, A., Ginsborg, J. and Peers. I. (2002) Development and disadvantage: implications for the early years and beyond. International Journal of Language and Communication Disorders 37 (1), 3-15.

Long, M.H. (1981) Input, Interaction and Second Language Acquisition. In Winnitz (ed.): Native Language and Foreign Acquisition. Annals of the New York Academy of Sciences 379, 259-78.

Long, M.H. (1983) Native Speaker / Non-native Speaker Conversation and the negotiation of Comprehensible Input. Applied Linguistics 4 (2), 126-41. 
Long, M.H. (1996) The Role of the Linguistic Environment in Second Language Acquisition. In W.C. Ritchie and T.K. Bhatia (eds.) Handbook of Second Language Acquisition. San Diego: Academic Press.

Mehan, H. (1985) The Structure of Classroom Discourse. In T.A. Van Dijk (ed.) Handbook of Discourse Analysis, Vol 3, Discourse and Dialogue. London: Academic Press.

Mercer, N. (1995) The Guided Construction of Knowledge. Clevedon, UK: Multilingual Matters.

Morgan, N. and Saxton, J. (1991) Teaching, Questioning and Learning. London: Routlege.

Mroz, M., Smith, F. and Hardman, F. (2000) The Discourse of the Literacy Hour. Cambridge Journal of Education 30 (3), 379-390.

Nassaji, H. and Wells, G. (2000) What's the use of triadic dialogue? An investigation of teacher-student interaction. Applied Linguistics 21 (3), 376-406.

Nathan, Stackhouse, J. Goulandris, N. and Snowling, M. (2004) Educational consequences of developmental speech disorder: Key Stage 1 National Curriculum assessment results in English and mathematics. British Journal of Educational Psychology 74, 173-186. 
Nelson, K. E. (1989) Strategies for first language teaching. In M. Rice and R. Schiefelbusch (eds.) The Teachability of Language. Baltimore: Brooks.

Nelson, K. E., Welsch, J., Camarata, S., Butkovsky, L. and Camarata, M. (1995) Available input for language-impaired children and younger children of matched language levels. First Language 15/1 (43), 1-17.

Nelson, K. E., Camarata, S., Welsh, J., Butkovsky, L. and Camarata, M. (1996) Effects of imitative and conversational recasting treatment on the acquisition of grammar in children with specific language impairment and younger language-normal children. Journal of Speech and Hearing Research 39, 850-859.

Norman, K. 1992. (ed.) Thinking Voices. London: Hodder and Stoughton.

Nystrand, M. (1997) Opening Dialogue: Understanding the Dynamics of Language and Learning in the English Classroom. New York: Teachers College Press.

O’Connor, M.C. and Michaels, S. (1996) Shifting Participant Frameworks:

Orchestrating Thinking Practices in Group Discussion. In D. Hicks (ed.) Discourse, Learning and Schooling. New York: Cambridge University Press.

Pica, T., Kanagy, R. and Falodun, J. (1993) Choosing and using Communicative Tasks for Second Language Instruction and Research. In G. Crookes and S. Gass (eds.) Tasks and Language Learning. Clevedon: Multilingual Matters. 
Radford, J. and Tarplee, C. (2000) The management of conversational topic by a tenyear-old child with pragmatic difficulty. Clinical Linguistics and Phonetics 14 (5), 387-403.

Ridley, J., Radford, J. and Mahon, M. (2002) How do teachers manage topic and repair? Child Language Teaching and Therapy 18 (1), 43-58.

Skidmore, D. (2000) From pedagogical dialogue to dialogical pedagogy. Language and Education 14 (4), 283-96.

Snow, C. E. (2001) Preventing reading difficulties in young children: Precursors and fallout. In T. Loveless (ed.) The Great Curriculum debate: How Should We Teach Reading and Math? The Brookings Institution: Washington D.C.

Stierer, B. and Maybin, J. (1994) (eds.) Language, Literacy and Learning in Educational Practice. Clevedon: Multilingual Matters.

Tharp, R. and Gallimore, R. (1998) A theory of teaching as assisted performance. In D. Faulkner, K. Littleton and M. Woodhead (eds.) Learning Relationships in the Classroom. London: Routledge / Open University.

Vygotsky, L.S. (1962) Thought and Language. Cambridge, MA: M.I.T. Press.

Wegerif, R. and Mercer, N. (1997) A dialogical framework for researching peer talk. 
In R. Wegerif and P. Scrimshaw (eds.) Computers and Talk in the Primary

Classroom. Clevedon: Multilingual Matters.

Wells, G. (1993) Re-evaluating the IRF Sequence: a proposal for the articulation of theories of activity and discourse for the analysis of teaching and learning in the classroom. Linguistics and Education 5, 1-37.

Wood, 1998. (2 ${ }^{\text {nd }}$ edn.) How Children Think and Learn. Oxford: Blackwell. 
Appendix 1: Key to transcription

(0.5) The number in brackets indicates silence by tenths of seconds.

(.) A dot enclosed in a bracket indicates a gap in the talk of less than twotenths of a second.

$=\quad$ The equals sign indicates 'latching' between utterances.

[ ] Square brackets between adjacent lines of concurrent speech indicate the onset and end of a spate of overlapping talk.

.hh A dot before an ' $h$ ' indicates speaker in-breath. The more h's the longer the breath.

hh An ' $h$ ' indicates an out-breath. The more h's the longer the breath.

((points) A description enclosed in brackets, and written in italics, indicates a nonverbal activity. For example ((points at picture)).

::: $\quad$ Colons indicate that the speaker has stretched the preceding sound or letter. The more colons the greater the extent of the stretching.

*** Indicates the presence of an unclear fragment of tape.

(guess) The words within a single bracket indicate the transcriber's best guess at an unclear utterance.

A full stop indicates a stopping fall in tone. It does not necessarily indicate the end of a sentence.

A comma indicates a 'continuing' intonation.

? $\quad$ A question mark indicates a rising inflection. It does not necessarily indicate a question.

$\uparrow \downarrow \quad$ Pointed arrows indicate a marked falling or rising intonational shift. They are placed immediately before the onset of the shift.

under Underlined fragments indicate speaker emphasis.

(Transcription style developed by Gail Jefferson, and reported in Hutchby and Wooffitt, 1999) 